\title{
Transducin $\gamma$-Subunit Sets Expression Levels of $\alpha$ - and $\beta$-Subunits and Is Crucial for Rod Viability
}

\author{
Ekaterina S. Lobanova, ${ }^{1}$ Stella Finkelstein, ${ }^{1}$ Rolf Herrmann, ${ }^{1}$ Yen-Ming Chen, ${ }^{2}$ Christopher Kessler, ${ }^{2}$ \\ Norman A. Michaud, ${ }^{3}$ Lynn H. Trieu, ${ }^{3}$ Katherine J. Strissel, ${ }^{3}$ Marie E. Burns, ${ }^{2}$ and Vadim Y. Arshavsky ${ }^{1}$ \\ ${ }^{1}$ Albert Eye Research Institute, Duke University, Durham, North Carolina 27710, ${ }^{2}$ Center for Neuroscience and Department of Ophthalmology and Vision \\ Science, University of California Davis, Davis, California 95618, and ${ }^{3}$ Massachusetts Eye and Ear Infirmary, Boston, Massachusetts 02114
}

Transducin is a prototypic heterotrimeric G-protein mediating visual signaling in vertebrate photoreceptor cells. Despite its central role in phototransduction, little is known about the mechanisms that regulate its expression and maintain approximately stoichiometric levels of the $\alpha$-and $\beta \gamma$-subunits. Here we demonstrate that the knock-out of transducin $\gamma$-subunit leads to a major downregulation of both $\alpha$ - and $\beta$-subunit proteins, despite nearly normal levels of the corresponding transcripts, and fairly rapid photoreceptor degeneration. Significant fractions of the remaining $\alpha$ - and $\beta$-subunits were mislocalized from the light-sensitive outer segment compartment of the rod. Yet, the tiny amount of the $\alpha$-subunit present in the outer segments of knock-out rods was sufficient to support light signaling, although with a markedly reduced sensitivity. These data indicate that the $\gamma$-subunit controls the expression level of the entire transducin heterotrimer and that heterotrimer formation is essential for normal transducin localization. They further suggest that the production of transducin $\beta$-subunit without its constitutive $\gamma$-subunit partner sufficiently stresses the cellular biosynthetic and/or chaperone machinery to induce cell death.

Key words: transducin; photoreceptor; G-proteins; cell death; protein expression; protein localization

\section{Introduction}

Heterotrimeric G-proteins have been long recognized to mediate a vast number of intracellular signaling pathways; however, the cellular mechanisms responsible for their assembly and intracellular targeting remain far from understood (for review, see Marrari et al., 2007). Transducin (or $G_{t}$ ) is one of the best studied G-proteins. It mediates phototransduction between the lightactivated visual pigment rhodopsin and the effector enzyme cGMP phosphodiesterase (PDE) in retinal rods [for review, see Burns and Baylor (2001), Fain et al. (2001), and Arshavsky et al. (2002)]. The rate of transducin activation, which is a key determinant in setting the photoreceptor's sensitivity to light (Pugh and Lamb, 1993), depends on transducin concentration in photoreceptor outer segments (Sokolov et al., 2002), and in fact, transducin concentration and the rate of its activation are very similar in rods of many vertebrate species (for review, see Pugh et al., 1999). However, the outer segment content of transducin changes during the normal diurnal cycle as a result of its reversible light-driven translocation from the outer segment to other cellular compartments (for review, see Calvert et al., 2006). This phenomenon is thought to contribute to photoreceptor light ad-

Received Sept. 13, 2007; revised Feb. 19, 2008; accepted Feb. 21, 2008

This work was supported by National Institutes of Health (NIH) Grants EY10336 (V.Y.A.) and EY 14047 (M.E.B.) and NIH Core Grant for Vision Research EY5722 to Duke University. We thank S. A. Baker, N. P. Skiba, and V. I. Govardovskii for helpful discussions, C. Bowes Rickman for advice in performing qRT-PCR, Y. Hao for performing electron microscopy, and P. S. Ferry-Leeper for help in maintaining mouse colonies.

Correspondence should be addressed to Vadim Y. Arshavsky, Duke University Eye Center, 5008 AERI, 2351 Erwin Road, Durham, NC 27710. E-mail: vadim.arshavsky@duke.edu.

DOI:10.1523/JNEUROSCI.0338-08.2008

Copyright $\odot 2008$ Society for Neuroscience $\quad$ 0270-6474/08/283510-11\$15.00/0 aptation by reducing transducin activation rate at bright light (Sokolov et al., 2002). Therefore, it is fundamentally important to understand the mechanisms controlling transducin heterotrimer expression and similar levels of its individual $\mathrm{G} \alpha_{\mathrm{t}}$ and $\mathrm{G} \beta_{1} \gamma_{1}$ subunits.

Previous work has demonstrated that knock-out of $\mathrm{G} \alpha_{\mathrm{t}}$ makes rods completely insensitive to light but neither affects the expression level of $\mathrm{G} \beta_{1} \gamma_{1}$ nor causes photoreceptor degeneration (Calvert et al., 2000). We have now characterized the reciprocal model of the $\mathrm{G} \gamma_{1}$ knock-out mouse and revealed a very different phenotype. The lack of $\mathrm{G} \gamma_{1}$ caused $>25$-fold reduction in the protein levels of both $\mathrm{G} \beta_{1}$ and $\mathrm{G} \alpha_{\mathrm{t}}$, despite nearly unchanged levels of the corresponding mRNAs, indicating that the total amount of transducin in rods is set by the amount of functional G $\beta_{1} \gamma_{1}$. The remaining $\mathrm{G} \alpha_{\mathrm{t}}$ was distributed throughout the entire rod cell, demonstrating that the formation of transducin heterotrimer is required for its normal outer segment localization. Interestingly, the small fraction of $\mathrm{G} \alpha_{\mathrm{t}}$ present in the outer segments of knockout rods was sufficient to support photoresponses, although with $\sim 70$-fold reduction in sensitivity. We also found that, unlike the knock-out of $\mathrm{G} \alpha, \mathrm{G} \gamma_{1}$ knock-out causes gradual retinal degeneration with photoreceptor loss observed as early as at 4 weeks of age. Overall, these data provide a striking in vivo example of how mutual interactions between individual subunits affect G-protein expression, localization, signaling, and eventually cell health.

\section{Materials and Methods}

Animals. The $\mathrm{G} \gamma_{1}$ knock-out mouse was licensed from Deltagen (San Mateo, CA). The company provided two breeding pairs of heterozygous mice, and animals used in this study were obtained by sibling mating. The 


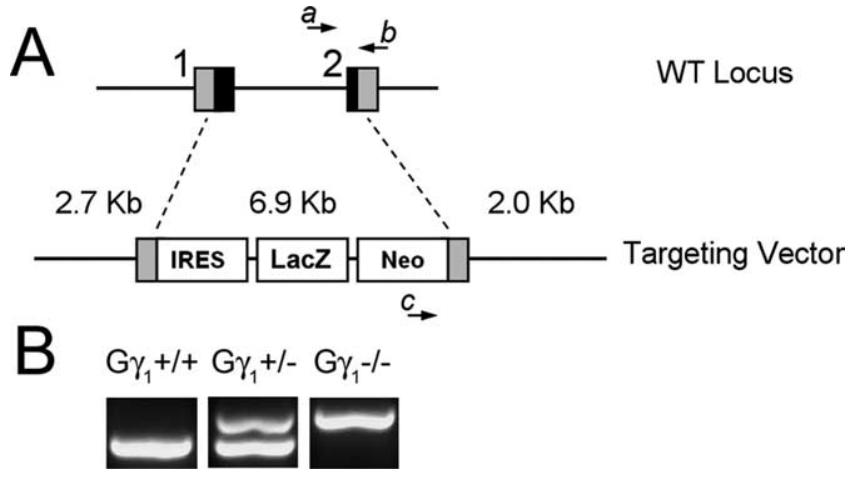

Figure 1. Knock-out strategy and genotyping of the $\mathrm{G} \gamma_{1}$ knock-out mouse. A, Structures of the wild-type Gngt 1 gene locus containing exons 1 and 2 and the targeting vector. Dark boxes represent regions of the $\mathrm{G} \gamma_{1}$ coding sequence (amino acid residues $17-44$ ), which was replaced with a $6.9 \mathrm{~kb}$ IRES-lacZ reporter and neomycin-resistance cassette (IRES-lacZ-neo). B, Genotyping of Gngt 1 knock-out mice by multiplex PCR. We used a mixture of three primers: a (5-TGC TCA CTC TCC TCC ATC TTC ACA C-3), b (5-CTG GAA TCC CCT TCA CTA GAG GGT C-3), and c (5-GAC GAG TTC TTC TGA GGG GAT CGA TC-3), which amplify the 412 bp product from the Gngt1 gene ( $a$ and $b$ ) and/or the $617 \mathrm{bp}$ product from the knock-out allele containing a fragment of the neomycin resistance cassette (b and c). Genomic DNA was isolated from the mouse tail tips using the DNeasy Tissue kit (QIAGEN).

knock-out construct map is illustrated in Figure 1, and the genotyping strategy is described in figure legend. Mice were generated on the 129/ OlaHsd background and back-crossed with C57BL/6 (Charles River, Wilmington, MA) for at least six generations. The $\mathrm{G} \alpha_{\mathrm{t}}$ knock-out mouse was kindly provided by J. Lem (Tufts University, Medford, MA). The phosducin knock-out mouse was described by Sokolov et al. (2004). All animals were maintained under the standard $12 / 12 \mathrm{~h}$ light/dark cycle and dark adapted for at least $12 \mathrm{~h}$ before experiments. Animal light adaptation was performed as described by Lobanova et al. (2007).

Antibodies and Western blotting. Rabbit antibodies SC-379 against $\mathrm{G} \beta_{1}$, SC-380 against $\mathrm{G} \beta_{2}, \mathrm{SC}-381$ against $\mathrm{G} \beta_{3}, \mathrm{SC}-382$ against $\mathrm{G} \beta_{4}$, SC389 against $\mathrm{G} \alpha_{\mathrm{t}}, \mathrm{SC}-373$ against $\mathrm{G} \gamma_{1}, \mathrm{SC}-374$ against $\mathrm{G} \gamma_{2}, \mathrm{SC}-375$ against $\mathrm{G} \gamma_{3}$, and G-8 against rhodopsin kinase were from Santa Cruz Biotechnology (Santa Cruz, CA). Rabbit antibody against $\mathrm{G} \gamma_{\mathrm{c}}$ was from CytoSignal Research Products (Irvine, CA). Rabbit antibody PA1-7 against rod arrestin was from Affinity Bioreagents (Golden, CO). Rabbit antibodies against recoverin, guanylate cyclase activating protein 1 (GCAP1), GCAP2, retina guanylate cyclase isoform 1 (retGC1), and retGC2 were a gift from A. M. Dizhoor (Pennsylvania College of Optometry, Elkins Park, PA). Rabbit antibody against rod PDE $\gamma$-subunit was a gift from R. H. Cote (University of New Hampshire, Durham, NH). Rabbit antibodies against rod cGMP phosphodiesterase $\alpha$ and $\beta$ subunits were a gift from N. O. Artemyev (University of Iowa, Iowa City, IA). Mouse monoclonal anti-rhodopsin antibody 4D2 was a gift from R. S. Molday (University of British Columbia, Vancouver, British Columbia, Canada). Rabbit anti-phosducin-like protein (PhLP) antibody was a gift from B. M. Willardson (Brigham Young University, Provo, UT). Rabbit antiG $\beta 5$ antibody was a gift from W. F. Simonds (National Institutes of Health-National Institute of Diabetes and Digestive and Kidney Diseases). Sheep anti-regulator of G-protein signaling 9 (RGS9) antibody is described by Makino et al. (1999) and anti-phosducin antibody by Sokolov et al. (2004). Secondary antibodies for Western blotting were goat or donkey conjugated with Alexa Fluor 680 (Invitrogen, Carlsbad, CA). Protein bands were visualized and quantified using the Odyssey Infrared Imaging System (LI-COR Biosciences, Bad Homburg, Germany).

Histological techniques. Plastic-embedded cross sections $(1 \mu \mathrm{m})$ of the mouse retina were prepared as by Sokolov et al. (2004) and stained with toluidine blue for light microscopy. Electron microscopy was performed as by Petters et al. (1997). Serial tangential sectioning of flat-mounted frozen mouse retinas was initially described by Sokolov et al. (2002) and performed as by Lobanova et al. (2007).

$m R N A$ purification and real-time quantitative reverse transcription-
PCR. The transcript levels for $\mathrm{G} \alpha_{\mathrm{t}}, \mathrm{G} \beta_{1}$, and $\mathrm{G} \gamma_{1}$ in the knock-out, heterozygous, and wild-type (WT) mice were measured using quantitative reverse transcription (qRT)-PCR (Livak and Schmittgen, 2001; Pfaffl, 2001). Both retinas were removed and stored in RNAlater solution (Ambion, Austin, TX) until total RNA was extracted using the RNAeasy Protect Mini Kit (QIAGEN, Valencia, CA). mRNA concentration was determined using the Quant-IT RiboGreen RNA Assay (Invitrogen) on a TD-700 Fluorometer (Turner Designs, Sunnyvale, CA). cDNA was synthesized from $0.5-1 \mu \mathrm{g}$ of total RNA using Superscript III Reverse Transcriptase and oligo- $(\mathrm{dT})_{20}$ primer (Invitrogen) according to the manufacturer's instructions. Signals of $\mathrm{G} \alpha_{\mathrm{t}}, \mathrm{G} \beta_{1}$, and $\mathrm{G} \gamma_{1}$ mRNAs from each animal type were obtained on a sequence-detection system (iCycler iQ; Bio-Rad, Hercules, CA) using SYBR-Green (IQ SYBR Green SuperMix; Bio-Rad) and normalized to an endogenous reference [glyceraldehyde3-phosphate dehydrogenase (GAPDH)]. At least two animals of each type were used, and the PCR analysis was repeated three times for each animal. PCR was performed as follows: one cycle at $95^{\circ} \mathrm{C}$ for $2 \mathrm{~min}, 40$ cycles at $95^{\circ} \mathrm{C}$ for $20 \mathrm{~s}$, one cycle at $55^{\circ} \mathrm{C}$ for $20 \mathrm{~s}$, and at $72^{\circ} \mathrm{C}$ for $20 \mathrm{~s}$.

The following primers were used. G $\alpha_{\mathrm{t}}$ : forward, $5^{\prime}$-TGA CCA CGC TCA ACA TTC AGT ATG; reverse, 5' -CAT ATC CTG GAG TCA CCA GAC G. G $\beta_{1}$ : forward, $5^{\prime}$-ACA ACC ACA TTT ACT GGA CAC ACT; reverse, $5^{\prime}$-ACC TGC TCT GTC AGC TTT GA. G $\gamma_{1}$ : forward, $5^{\prime}$-CCA GTG ATC AAC ATC GAA GAC CTG; reverse, 5' -TTC TTC AAT ATA ATC TCT CAC TTC TTC ACA ACA. GAPDH: forward, 5'-GTG AAG GTC GGT GTG AAC G; reverse, 5'-GTG GTG AAG ACA CCA GTA GAC TC. The standard curves for each set of primers were obtained with cDNA synthesized from $0.1,0.5,1,5,10$, and $50 \mathrm{ng}$ of wild-type RNA extracted from 30-d-old C57BL/6 mice. The slopes of all curves were similar and equal to $-3.48 \pm 0.09(n=3)$ for $\mathrm{G} \alpha_{\mathrm{t}} ;-3.49 \pm 0.09(n=4)$ for $\mathrm{G} \beta_{1} ;-3.46 \pm 0.03(n=3)$ for $\mathrm{G} \gamma_{1}$; and $-3.52 \pm 0.09(n=4)$ for GAPDH.

Protein quantification. Both retinas from a mouse were extracted under dim red illumination and sonicated in $250 \mu$ lof water. Rhodopsin concentration was determined in $100 \mu \mathrm{l}$ aliquots by difference spectroscopy using the molar extinction coefficient of $40,500 \mathrm{M}^{-1} \cdot \mathrm{cm}^{-1}$. The rest of the sample was used for quantitative Western blotting. For the preparation of transducin subunits' standards, the heterotrimer was purified from frozen bovine retinas (Ting et al., 1993), and $\mathrm{G} \alpha_{\mathrm{t}}$ was separated from $\mathrm{G} \beta_{1} \gamma_{1}$ on a $1 \mathrm{ml}$ Blue Sepharose column (GE Healthcare, Piscataway, NJ) according to Heck and Hofmann (2001). The purity of the resulting subunits was assessed to exceed $98 \%$. The concentration of each subunit was determined spectrophotometrically using calculated molar extinction coefficients at $280 \mathrm{~nm}$ of $36,507 \mathrm{M}^{-1} \cdot \mathrm{cm}^{-1}$ for $\mathrm{G} \alpha_{\mathrm{t}}$ (assuming that it contains a molecule of bound GDP) and $58,410 \mathrm{M}^{-1}$. $\mathrm{cm}^{-1}$ for $\mathrm{G} \beta_{1} \gamma_{1}$. Equimolar amounts of standards were mixed together in the SDS-PAGE sample buffer, and serial dilutions were run on the same gel as retina extracts. Bovine transducin subunits could be used for calibration because they share conservative antibody recognition sites with mouse.

Electroretinography. Electroretinograms were recorded using the Espion $\mathrm{E}^{2}$ system (DiagnoSYS, Littleton, MA) according to published methods (Saszik et al., 2002). Dark-adapted mice were anesthetized by intraperitoneal injection of a ketamine/xylazine mixture $(75 / 10 \mathrm{mg} / \mathrm{kg})$, their pupils were dilated with $1 \%$ cyclopentolate- $\mathrm{HCl}, 2.5 \%$ phenylephrine, and a drop of Gonak solution (Akorn, Buffalo Grove, IL) was placed on the cornea. The recording electrode was a silver fiber, and the reference electrode was a toothless alligator clip wetted with Gonak and attached to the mouse cheek. Mouse body temperature was maintained at $37^{\circ} \mathrm{C}$ using a Deltaphase Isothermal Pad (Braintree Scientific, Braintree, $\mathrm{MA})$.

Single-cell recording. Suction electrode recordings of rod outer segment currents were performed and analyzed as described by Krispel et al. (2003). Briefly, young mice (38-44 d postnatal) were dark adapted overnight, and the retinas were dissected under infrared light. Ten millisecond flashes of $500 \mathrm{~nm}$ light of calibrated intensity were delivered to a single rod held in the suction electrode filled with HEPES-based buffer. The chamber was perfused with bicarbonate-buffered Locke's solution and held at $37^{\circ} \mathrm{C}$. For some $\mathrm{G} \gamma_{1}$ knock-out rods, white light was needed to elicit saturating responses. Wild-type values given in Table 4 reflect the 

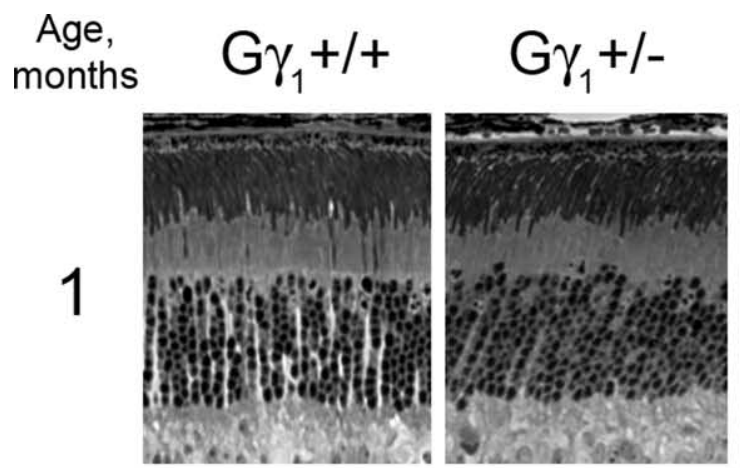

\section{$\mathrm{G} \gamma_{1}-/-$}
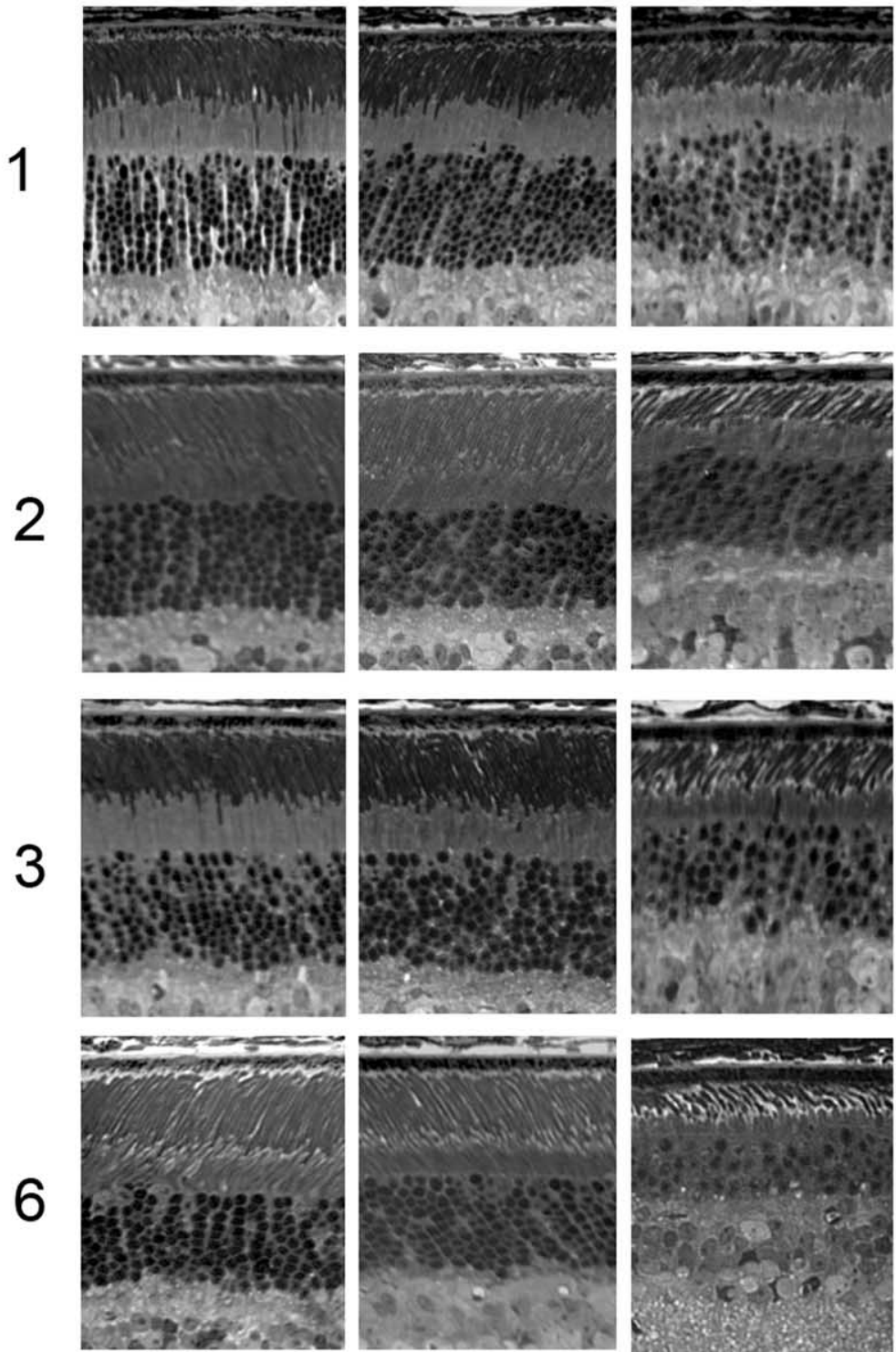
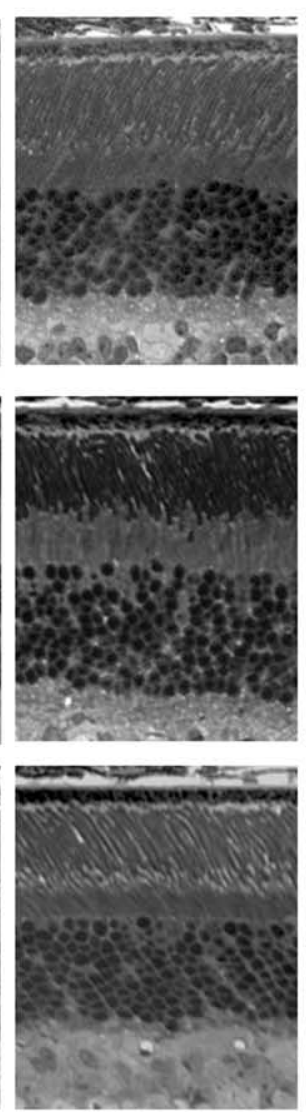
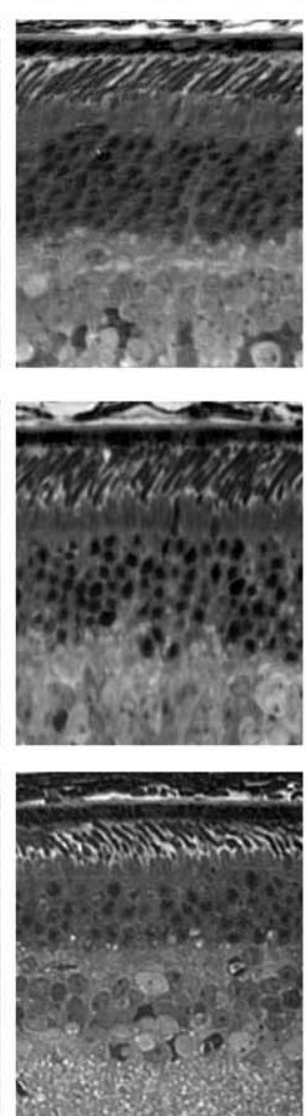

$\mathrm{G} \alpha_{t} / \mathrm{G} \gamma_{1} \mathrm{KO}$
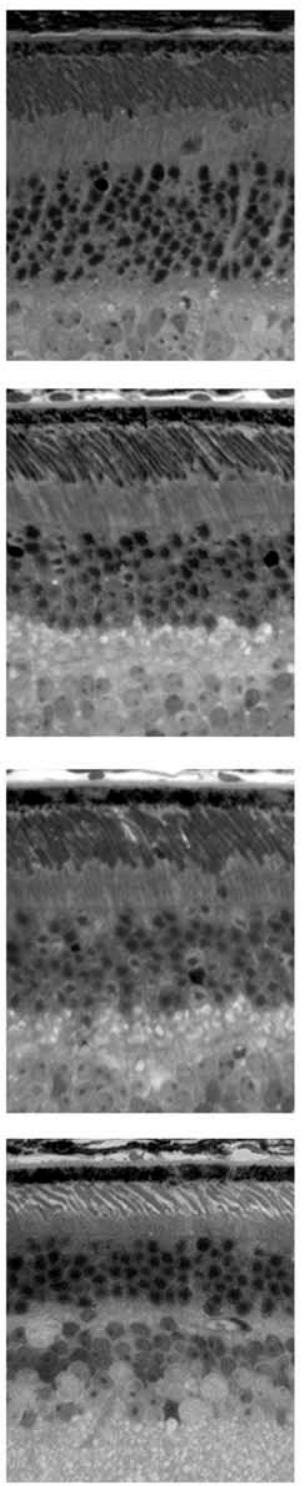
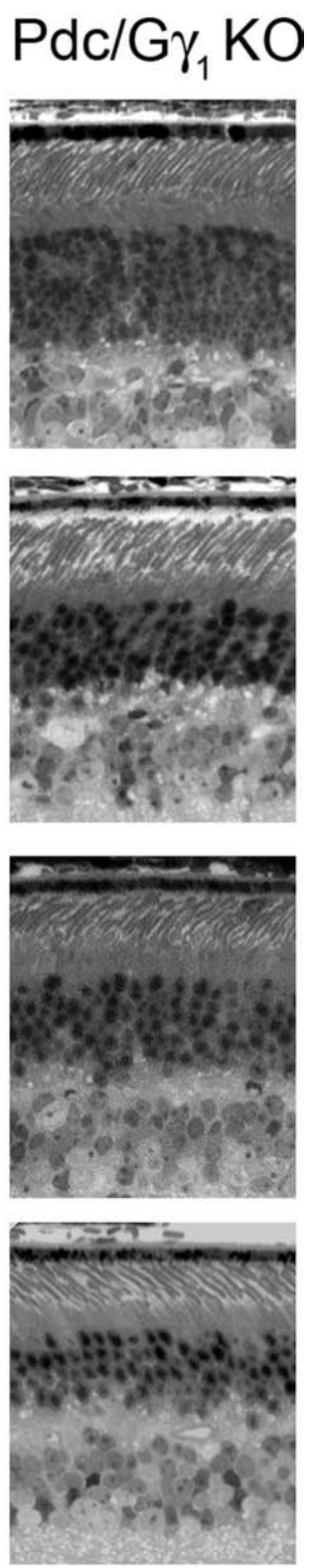

Figure 2. Comparative analysis of retina morphology in $\mathrm{G} \gamma_{1}$ knock-out $(-/-)$, heterozygous $(+/-)$, and wild-type littermates $(+/+)$ and $\mathrm{G} \alpha_{\mathrm{t}} / \mathrm{G} \gamma_{1}$ double knock-out (KO) and phosducin $(\mathrm{Pdc}) / \mathrm{G} \gamma_{1}$ double knock-out mice. Animals were killed at indicated ages, retinas were embedded in plastic, and $1 \mu \mathrm{m}$ cross sections were stained by toluidine blue and analyzed using a Nikon (Tokyo, Japan) Eclipse 90i microscope.

mean parameters obtained from $\mathrm{C} 57 \mathrm{BL} / 6$ mice recorded with the same solutions as those used for the $\mathrm{G} \gamma_{1}$ knock-out recordings. For cellular noise measurements, membrane currents were recorded in darkness and then in saturating light, and the power spectra of the two were subtracted (dark - light). The total cellular dark noise variance was determined for each cell by integrating the difference spectra over the bandwidth $0.1-20$ $\mathrm{Hz}$. In three $\mathrm{G} \gamma_{1}$ knock-out rods, the cellular dark noise was too small to be discernible; that is, integration of the difference spectra yielded a small negative number, and a zero value was recorded instead to calculate the mean. Average dark currents for rods used for noise analysis were similar (WT, $11.0 \pm 1.3 \mathrm{pA} ; n=8 ; \mathrm{G} \gamma_{1}$ knock-out, $9.5 \pm 1.0 \mathrm{pA} ; n=9 ; p=0.35$ ) Amplification constants were determined by fitting Equation 20 of Pugh and Lamb (1993) to the early rising phases of each cell's flash response family, assuming effective collecting areas of $0.4 \mu \mathrm{m}$ for wild-type rods and $0.27 \mu \mathrm{m}$ for $\mathrm{G} \gamma_{1}$ knock-out rods, based on the difference in their outer segment lengths at that age.

\section{Results}

Progressive photoreceptor loss in $\mathrm{G} \gamma_{1}$ knock-out mice

The strategy used for obtaining the $\mathrm{G} \gamma_{1}$ knock-out mouse is illustrated in Figure 1 and described in Materials and Methods. The analysis of retinal morphology in these mice revealed a progressive pattern of photoreceptor degeneration (Fig. 2). At 1 month of age, the length of rod outer segments was reduced by approximately one-third, and distinct gaps among individual rod outer segments were evident after electron microscopy analysis (Fig. 3). At 2 months, outer segment loss was more prominent and accompanied by a detectable change in the number of photoreceptor nuclei present in the outer nuclear layer. By 6 months, the majority of rods were gone with only approximately three to four nuclei remaining per row (compared with $\sim 10-11$ in wildtype mice of this age), and the outer segments were further short- 

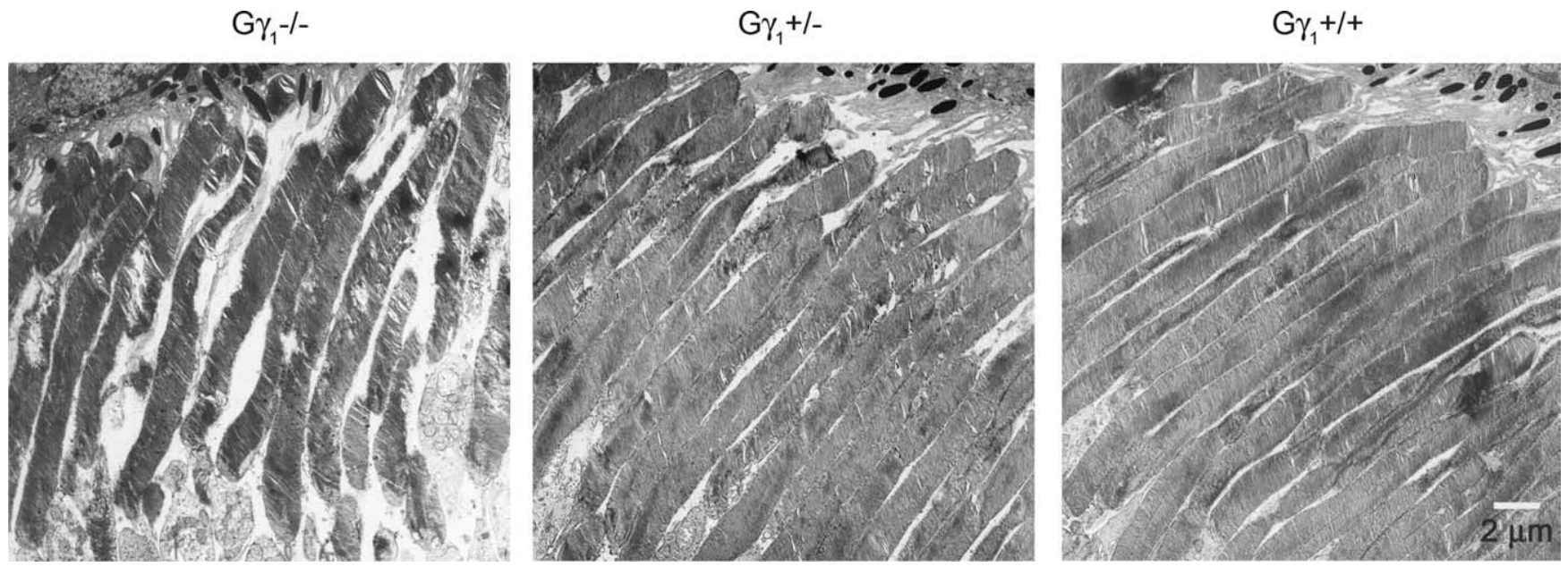

Figure 3. Transmission electron microscopy of rod outer segments from $0.065 \mu \mathrm{m}$ retina cross sections from the 1-month-old $\mathrm{G} \gamma_{1}$ knock-out mouse and its heterozygote and wild-type littermates. The pictures were taken at $2500 \times$ magnification.

ened. In contrast, heterozygote mice showed no signs of degeneration, and their photoreceptor morphology was indistinguishable from that in the wild-type mice at all analyzed ages (Figs. 2, 3).

This phenotype is entirely different from that of the $\mathrm{G} \alpha \mathrm{t}$ knock-out, which is characterized by normal photoreceptor morphology and only age-dependent photoreceptor loss similar to that observed in wild-type mice (Calvert et al., 2000). Therefore, we tested which phenotype prevails in the double knock-out mice lacking both $\mathrm{G} \alpha_{\mathrm{t}}$ and $\mathrm{G} \gamma_{1}$ and found that photoreceptor degeneration in the double knock-out progresses with similar rate as in the single $G \gamma_{1}$ knock-out (Fig. 2). The same pattern was observed for the double knock-out mice lacking both $\mathrm{G} \gamma_{1}$ and phosducin, the second major $\mathrm{G} \beta_{1} \gamma_{1}$ binding partner in rods (Fig. 2 ). Raising the $\mathrm{G} \gamma_{1}$ knock-out mice in complete darkness did not cause a marked difference in the progression of degeneration (data not shown).

\section{$\mathrm{G} \gamma_{1}$ knock-out mice are characterized by significant downregulation of $\mathrm{G} \boldsymbol{\beta}_{\mathbf{1}}$ and $\mathrm{G} \boldsymbol{\alpha}_{\mathrm{t}}$}

We compared the amounts of several rod-specific signaling proteins in retinal lysates of $\mathrm{G} \gamma_{1}$ knock-out and wild-type mice at postnatal days 31-33 (Fig. 4A), when rod outer segments are reasonably developed, yet their loss as a result of photoreceptor degeneration is just beginning. At this age, the rhodopsin content, which reflects the amount of rod outer segment membrane material in the retina, was $169 \pm 13 \mathrm{pmol} / \mathrm{retina}(\mathrm{SEM} ; n=8)$ in $\mathrm{G} \gamma_{1}$ knock-outs compared with $292 \pm 33 \mathrm{pmol} / \mathrm{retina}(n=8)$ in wild-type and $313 \pm 43 \mathrm{pmol} /$ retina $(n=3)$ in heterozygous mice. This decrease is likely to reflect a combination of the reduced rod outer segment length in $\mathrm{G} \gamma_{1}$ knock-out mice and some photoreceptor loss beginning even at this early age.

The only major effect of the $\mathrm{G} \gamma_{1}$ knock-out was a significant downregulation of both $\mathrm{G} \alpha_{\mathrm{t}}$ and $\mathrm{G} \beta_{1}$ (Fig. $4 A$ ). In contrast, the majority of other outer segment proteins, including cGMP phosphodiesterase subunits, two guanylate cyclase isoforms, their $\mathrm{Ca}^{2+}$ regulators GCAP1 and GCAP2, GTPase-activating protein RGS9, rhodopsin kinase, and recoverin, remained at the normal molar ratio to rhodopsin despite outer segment shortening. Phosducin was slightly downregulated, reminiscent of the reciprocal downregulation of $\mathrm{G} \beta_{1} \gamma_{1}$ in phosducin knock-out retinas (Sokolov et al., 2004). The relative levels of PhLP and arrestin, localized primarily outside rod outer segments in the dark, were elevated by $\sim 30-40 \%$. However, the increase in PhLP and arrestin is likely a simple consequence of normalizing the samples by rhodopsin content: a $40 \%$ reduction of rhodopsin in $\mathrm{G} \gamma_{1}$ knockouts is expected to yield $\sim 40 \%$ more inner segment proteins in each sample.

To quantify the reduction of $\mathrm{G} \alpha_{\mathrm{t}}, \mathrm{G} \beta_{1}$, and $\mathrm{G} \gamma_{1}$ expression in retinas of $\mathrm{G} \gamma_{1}$ knock-out and heterozygote mice, we determined the amount of each subunit in retinal homogenates of knock-out, heterozygous, and wild-type mice by quantitative Western blotting using purified transducin subunits as the standards (Fig. $4 B$, Tables 1, 2). We found that $\mathrm{G} \gamma_{1}$ knock-out retinas contained $\sim 4 \% \mathrm{G} \alpha_{\mathrm{t}}$ and $\sim 11 \% \mathrm{G} \beta_{1}$, whereas heterozygous retinas contained approximately two-thirds of wild-type amounts of each subunit. However, the reduction of $\mathrm{G} \beta_{1}$ in rods is even more significant than in whole retinas, because unlike $\mathrm{G} \alpha_{\mathrm{t}}$ and $\mathrm{G} \gamma_{1}$, an appreciable fraction $G \beta_{1}$ is expressed in the inner retina. This fraction was measured by the technique of serial sectioning/ Western blotting, which takes advantage of the layered anatomy of the retina (Sokolov et al., 2002; Strissel et al., 2006; Song et al., 2007). We obtained progressive 20 - $\mu$ m-thick tangential sections throughout the entire retina from the light-adapted $\mathrm{G} \gamma_{1}$ knockout and wild-type mice and analyzed the distribution of $\mathrm{G} \beta_{1}$ among the individual sections by quantitative immunoblotting (Fig. 4C). In wild-type mice, the majority of $\mathrm{G} \beta_{1}$ and the entire $\mathrm{G} \gamma_{1}$ were present in the first six sections representing the photoreceptor layer, which is consistent with the well documented $\mathrm{G} \beta_{1} \gamma_{1}$ distribution throughout the entire length of light-adapted rods (Sokolov et al., 2004). The fraction of $\mathrm{G} \beta_{1}$ expressed in the inner retina (sections $7-12$ ) was $8.6 \pm 3.2 \%$ of the total $(n=4)$. In contrast, the majority of $\mathrm{G} \beta_{1}$ in $\mathrm{G} \gamma_{1}$ knock-out mice was found in the inner retina ( $82 \pm 5 \%$ total; $n=2$ ) (Fig. $4 C$, bottom, sections $6-11$ ) as a consequence of major $\mathrm{G} \beta_{1}$ downregulation in rods. Therefore, only $\sim 18 \%$ of the $G \beta_{1}$ present in the knock-out retinas is actually expressed in the rods, which corresponds to only $\sim 3.4 \%$ of the amount of $\mathrm{G} \beta_{1}$ normally present in rods of wild-type mice (Table 2). Immunoprecipitation failed to detect any other G-protein $\gamma$-subunits bound to G $\beta_{1}$ and Western blotting did not reveal any compensatory upregulation of $\mathrm{G} \gamma_{2}, \mathrm{G} \gamma_{3}$, and $\mathrm{G} \gamma_{\mathrm{c}}$ [previously documented in the outer retina in addition to $G \gamma_{1}$ (Peng et al., 1992) ], nor of $G \beta_{2}, G \beta_{3}, G \beta_{4}$, and $G \beta_{5}$ (data not shown; see Materials and Methods for antibodies used). 


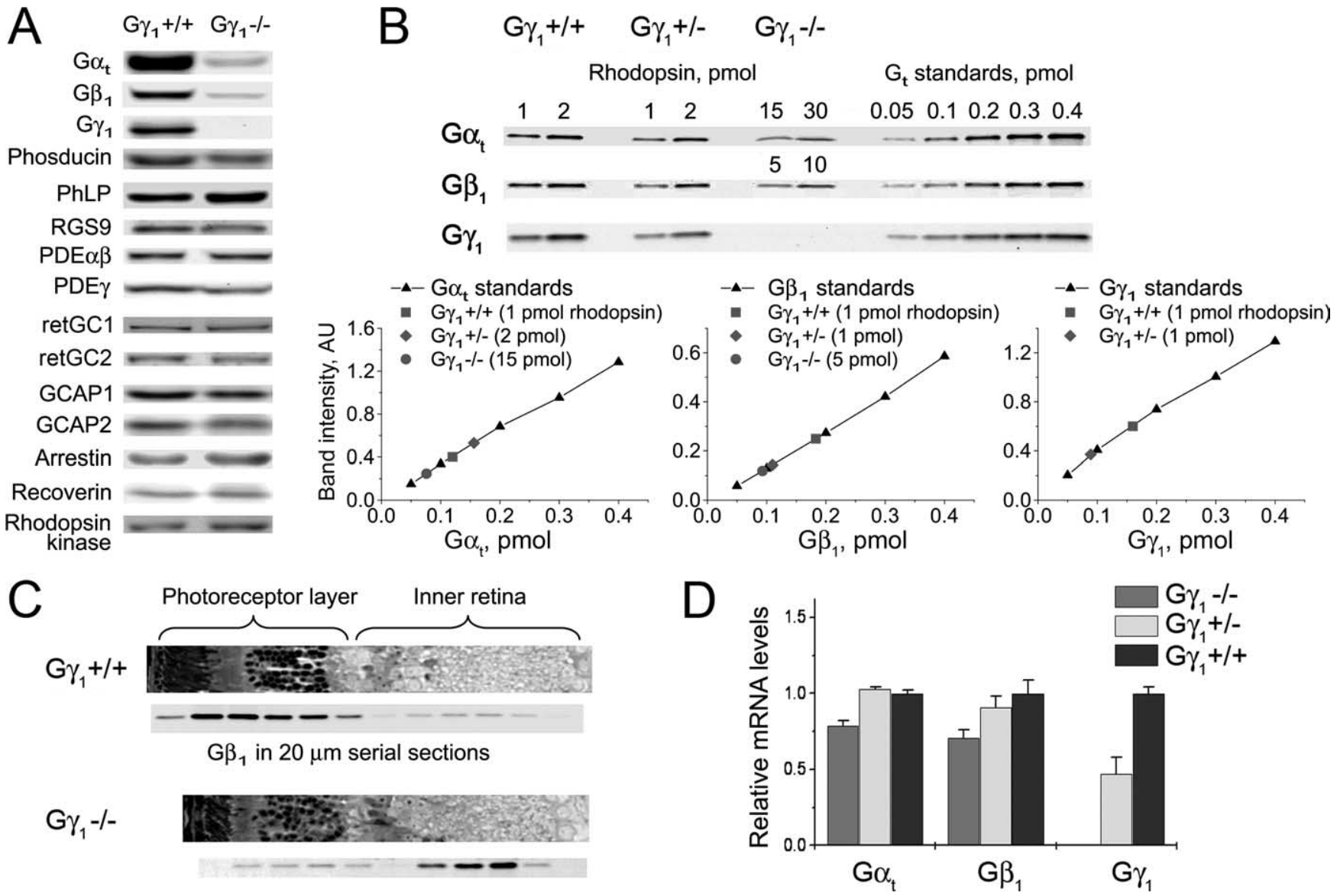

Figure 4. The expression of transducin and other major photoreceptor proteins in the retinas of 31- to 33- $\mathrm{d}$-old $\mathrm{G} \gamma_{1}$ knock-out mice. $A$, Western blots of proteins in the retina lysates containing $5 \mathrm{pmol}$ of rhodopsin. Each determination was repeated for at least three pairs of wild-type and knock-out animals. $\boldsymbol{B}$, Quantification of transducin subunit amounts in whole retinas from $\mathrm{G} \gamma_{1}$ knock-out, heterozygote, and wild-type littermates. Retina lysate aliquots containing indicated amounts of rhodopsin were separated by SDS-PAGE along with $0.05,0.1,0.2,0.3$, and $0.4 \mathrm{pmol}$ of transducin standards and immunoblotted using antibodies against each subunit. The examples of calibration curves for each subunit are shown below the blots. The results from multiple experiments are summarized in Table 1. C, The distribution of $\mathrm{G} \beta_{1}$ in $20 \mu \mathrm{m}$ serial tangential sections throughout the entire light-adapted retina of wild-type and $\mathrm{G} \gamma_{1}$ knock-out mice was analyzed by Western blotting. Each section was solubilized in either 40 (knock-out) or 60 (wild-type) $\mu$ l of SDS-PAGE sample buffer, and $10 \mu$ laliquots were subjected to electrophoresis. The final blots were scanned at the excitation laser intensity optimized for attaining signal linearity in each case. The representative cross sections of each retina type are shown above the corresponding Western blot panes; note that the photoreceptor layer in knock-out retinas is approximately one section thinner than in wild type because of ongoing degeneration. $\boldsymbol{D}$, Transcript levels of transducin subunits in $G \gamma_{1}$ knock-out, heterozygote, and wild-type littermates. Quantitative RT-PCR of each transcript was conducted for two animals of each type as described in Materials and Methods. The relative mRNA expression level in each sample was normalized to the fluorescence of GAPDH and shown as the fraction of wild type.

Table 1. Expression levels of the $G_{t}$ subunits in whole retinas of 31- to 33-d-old wild-type, $\mathrm{G} \gamma_{1}$ knock-out, and heterozygote mice presented as percentages of rhodopsin (mean \pm SEM)

\begin{tabular}{lrrr}
\hline & $\mathrm{G} \alpha_{\mathrm{t}}$ & $\mathrm{G} \beta_{1}$ & $\mathrm{G} \gamma_{1}$ \\
\hline WT & $12.5 \pm 1.9(n=7)$ & $17.9 \pm 3.2(n=8)$ & $16.9 \pm 2.1(n=3)$ \\
$\mathrm{G} \gamma_{1}+/-$ & $7.8 \pm 0.2(n=4)$ & $12.4 \pm 1.7(n=4)$ & $10.4 \pm 0.7(n=4)$ \\
$\mathrm{G} \gamma_{1}-/-$ & $0.49 \pm 0.08(n=7)$ & $1.9 \pm 0.3(n=8)$ & \\
\hline
\end{tabular}

Table 2. The amounts of $G_{t}$ subunits expressed in rods of $G \gamma_{1}$ and heterozygote mice expressed as percentages of their amounts in wild-type rods

\begin{tabular}{lccc}
\hline & $\mathrm{G} \alpha_{\mathrm{t}}$ & $\mathrm{G} \beta_{1}$ & $\mathrm{G} \gamma_{1}$ \\
\hline $\mathrm{G} \gamma_{1}+/-$ & 63 & 66 & 62 \\
$\mathrm{G} \gamma_{1}-/-$ & 3.9 & 3.4 & \\
\hline
\end{tabular}

The numbers were calculated from the mean values shown in Table 1 and, in the case of $G \beta_{1}$, corrected for its inner retina content.

$\mathrm{G} \gamma_{1}$ knock-out does not significantly affect the expression of $\mathrm{G} \boldsymbol{\alpha}_{\mathrm{t}}$ and $\mathrm{G} \boldsymbol{\beta}_{1}$ mRNA

To analyze whether the reduction of $\mathrm{G} \alpha_{\mathrm{t}}$ and $\mathrm{G} \beta_{1}$ in $\mathrm{G} \gamma_{1}$ knockout rods may have resulted from reduced amounts of the corre- sponding transcripts, we determined their mRNA levels by qRTPCR (Fig. 4D). Knocking out $\mathrm{G} \gamma_{1}$ caused only a modest reduction in the mRNA levels of the other subunits $(21 \pm 3 \%$ for $\mathrm{G} \alpha_{\mathrm{t}}$ and $29 \pm 5 \%$ for $\mathrm{G} \beta_{1}$ ), which could be explained, at least in part, by the cell loss resulting from ongoing rod degeneration. Clearly, this effect cannot explain the $>96 \%$ protein loss, indicating that the latter is mediated primarily by posttranslational mechanisms. Heterozygous animals contained normal levels of $\mathrm{G} \alpha_{\mathrm{t}}$ and $\mathrm{G} \beta_{1}$ mRNAs and about one-half $(47 \pm 11 \%$ of the wild type) of the normal level of $\mathrm{G} \gamma_{1}$ mRNA. Therefore, the $\mathrm{G} \gamma_{1}$ protein reduction in the heterozygous mouse reflects the gene dosage effect, whereas the partial reduction in $\mathrm{G} \alpha_{\mathrm{t}}$ and $\mathrm{G} \beta_{1}$ proteins in this mouse is likely to be consequential to the reduction in $\mathrm{G} \gamma_{1}$.

\section{$\mathrm{G} \boldsymbol{\alpha}_{\mathrm{t}}$ and $\mathrm{G} \boldsymbol{\beta}_{1}$ are mislocalized in $\mathrm{G} \gamma_{1}$ knock-out rods}

We next analyzed the intracellular localization of $\mathrm{G} \alpha_{\mathrm{t}}$ and $\mathrm{G} \beta_{1}$ in $\mathrm{G} \gamma_{1}$ knock-out rods. The drastic downregulation of both subunits did not permit us to use the common immunostaining approach because of comparable levels of nonspecific staining and autofluorescence. Instead we once again used the serial sectioning/Western blotting technique and found that both sub- 


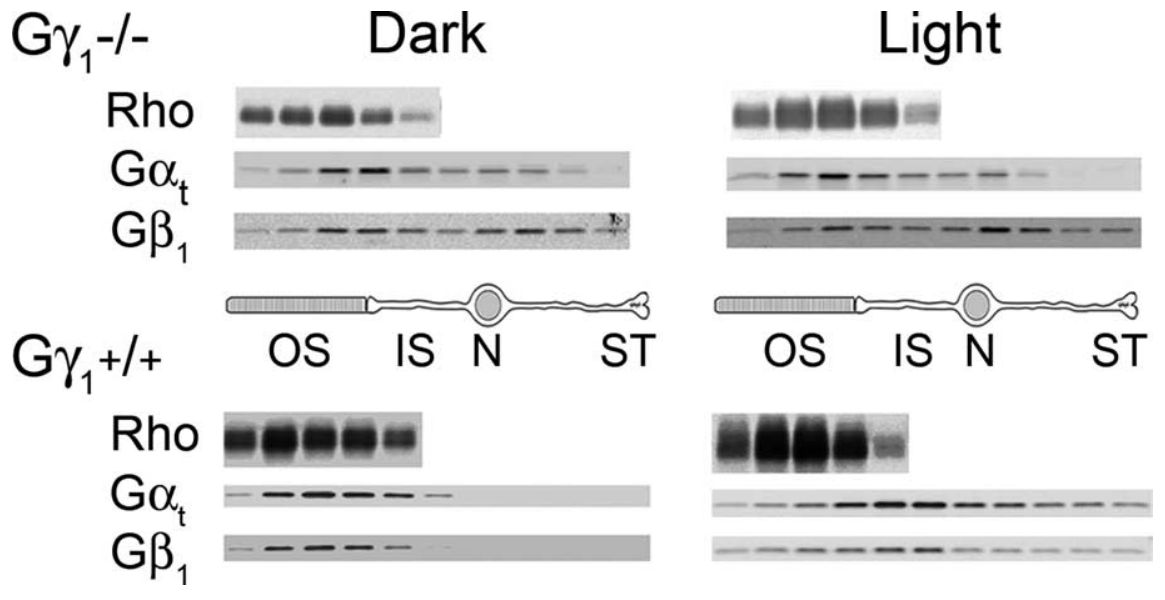

Figure 5. The distribution of $G \alpha_{t}$ and $G \beta_{1}$ in 10- $\mu$ m-thick tangential sections of the photoreceptor layer from $G \gamma_{1}$ knock-out and wild-type mice. Dark-adapted animals were anesthetized and either kept in the dark or exposed to 30 min of illumination, bleaching at least $80 \%$ rhodopsin by the end of the experiment. Their retinas were extracted and sections were obtained as by Lobanova et al. (2007). Each section from knock-out retinas was solubilized in $30 \mu \mathrm{l}$ and from wild type in $100 \mu \mathrm{l}$ of SDS-PAGE buffer, and $12 \mu$ laliquots were used for Western blotting. A small $1 \mu$ l aliquot from each sample was probed for the presence of rhodopsin (Rho), serving as the rod outer segment marker. The data are taken from one of at least three independent experiments. A schematic drawing of the rod cell is shown between the panels with subcellular compartments abbreviated as follows: $0 S$, outer segment; IS, inner segment; $N$, nucleus; $S T$, synaptic terminal.

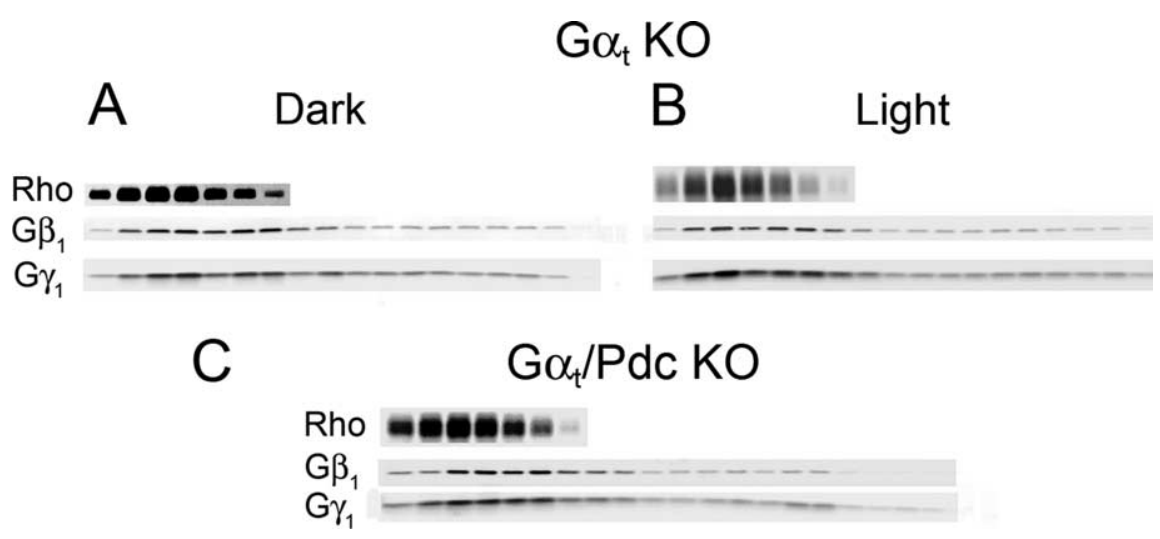

Figure 6. The distribution of $\mathrm{G} \beta_{1}$ and $\mathrm{G} \gamma_{1}$ in 5 - $\mu \mathrm{m}$-thick serial tangential sections of the photoreceptor layer in dark-adapted (A) or light-adapted (B) $G \alpha_{t}$ knock-out (KO) mice and in dark-adapted double $G \alpha_{t} /$ phosducin (Pdc) knock-out mouse (C). The experiments were performed as described in Figure 5 legend (wild type), except that the much higher $G \beta_{1} \gamma_{1}$ content in these animals enabled us to analyze proteins in thinner $5 \mu \mathrm{m}$ sections.

units are distributed throughout the entire length of both darkand light-adapted knock-out rods, with neither undergoing light-dependent translocation (Fig. 5, top). Therefore, the outer segments of $\mathrm{G} \gamma_{1}$ knock-out rods contain less than one-half of total $\mathrm{G} \alpha_{\mathrm{t}}$ and $\mathrm{G} \beta_{1}$ fractions (or $<2 \%$ of their normal amounts) under any conditions of illumination. This differs from wild-type rods, in which nearly all $\mathrm{G} \alpha_{\mathrm{t}}$ and $\mathrm{G} \beta_{1}$ are present in the same section as rhodopsin in the dark, indicating their localization to outer segments, whereas light causes their redistribution throughout the entire length of the photoreceptor layer (Fig. 5, bottom). Curiously, the distribution of $\mathrm{G} \beta_{1}$ (and to a lesser degree $\left.\mathrm{G} \alpha_{\mathrm{t}}\right)$ in $\mathrm{G} \gamma_{1}$ knock-out rods had two peaks, one at the outer/ inner segment border and another at the nuclear region, although the cause of such distribution is not clear.

The observation that a large fraction of $\mathrm{G} \alpha_{\mathrm{t}}$ is mislocalized from rod outer segments of the $G \gamma_{1}$ knock-out complements immunohistochemical results showing mislocalization of $\mathrm{G} \beta_{1} \gamma_{1}$ in $\mathrm{G} \alpha_{\mathrm{t}} /$ rhodopsin kinase double knock-out retinas (Zhang et al., 2003). Using a more quantitative approach of serial sectioning/
Western blotting in $\mathrm{G} \alpha_{\mathrm{t}}$ knock-out retinas (Fig. 6A,B), we found that the $\mathrm{G} \beta_{1} \gamma_{1}$ intracellular distribution, both in the dark and in bright light, is similar to $\mathrm{G} \alpha_{\mathrm{t}}$ distribution in the $\mathrm{G} \gamma_{1}$ knock-out mice. These data suggest that transducin localization to outer segments in the dark requires that its subunits form a heterotrimer. Because phosducin, a protein known to form a soluble complex with $G \beta_{1} \gamma_{1}$ (Loew et al., 1998; Lukov et al., 2004; Zhang et al., 2005), could potentially alter the distribution of $\mathrm{G} \beta_{1} \gamma_{1}$ in the absence of $\mathrm{G} \alpha_{\mathrm{t}}$, we performed an additional control in which we compared the intracellular distribution of $\mathrm{G} \beta_{1} \gamma_{1}$ in rods of dark-adapted $\mathrm{G} \alpha_{\mathrm{t}}$ knock-out mice with $\mathrm{G} \alpha_{\mathrm{t}} /$ phosducin double knock-outs (Fig. 6C) and found them to be virtually identical. Together, these data provide a compelling argument in support of the need for stable transducin heterotrimer formation for proper outer segment localization.

\section{The rods of $\mathrm{G} \gamma_{1}$ knock-out mice preserve the ability to respond to light}

To determine whether the small amount of $\mathrm{G} \alpha_{\mathrm{t}}$ preserved in the rod outer segments of $\mathrm{G} \gamma_{1}$ knock-out rods can support lightdriven electrical responses, we used electroretinography (ERG). This method is based on the recording of complex field potentials evoked in the retina by light using an electrode placed on the cornea (for review, see Pugh et al., 1998). A typical ERG response consists of the initial negative deflection, called the a-wave, which reflects the light-dependent current suppression in photoreceptor outer segments and is prominent only at relatively high light intensities, and the following b-wave, which primarily reflects the response of the bipolar cells functioning downstream from photoreceptors in the retina (Fig. 7A).

To estimate the rod component of the ERG responses from $\mathrm{G} \gamma_{1}$ knock-out mice, all recordings were conducted alongside wild-type mice and $\mathrm{G} \alpha_{\mathrm{t}}$ knock-out mice, in which rods do not respond to light, and ERG responses originate exclusively from cones (Calvert et al., 2000). We found that the amplitude of a-wave in $\mathrm{G} \gamma_{1}$ knock-out mice was approximately fivefold larger than in $\mathrm{G} \alpha_{\mathrm{t}}$ knock-out mice, indicating that $\mathrm{G} \gamma_{1}$ knock-out rods produce light-driven voltage responses (Fig. 7, Table 3). However, this amplitude was approximately threefold smaller than in wild-type mice, suggesting reduced light sensitivity in $G \gamma_{1}$ knock-out rods. The maximal b-wave amplitudes in $\mathrm{G} \gamma_{1}$ knockout and wild-type mice were nearly identical and approximately fourfold larger than in $\mathrm{G} \alpha_{\mathrm{t}}$ knock-outs, indicating that in sufficiently bright light, rod bipolar cells were fully activated by $\mathrm{G} \gamma_{1}$ knock-out rods. The half-saturating light intensity for b-wave was $\sim 2600$-fold higher than in wild-type mice. This could result from reduced light sensitivity of individual $\mathrm{G} \gamma_{1}$ knock-out rods, reduced rod numbers, and perhaps synaptic remodeling accompanying degeneration (Peng et al., 2003). 
To gain a more quantitative measure of rod phototransduction cascade in the absence of $G \gamma_{1}$, we used suction electrodes to record from individual rods of darkadapted $\mathrm{G} \gamma_{1}$ knock-out mice at 5-6 weeks of age (Fig. $8 \mathrm{~A}$, Table 4 ). These recordings were very difficult because of the early onset degeneration. In agreement with ERG findings, brief flashes generated responses whose amplitudes increased with increasing flash strength to maximal, saturating amplitudes that were only slightly smaller than that of wild-type rods. However, $G \gamma_{1}$ knock-out rods were considerably less light sensitive than normal. The flash strength needed to half-maximally activate $\mathrm{G} \gamma_{1}$ knock-out rods was $\sim 70$-fold brighter (Fig. 8 B, Table 4).

Unlike inactive transducin heterotrimer, free GDP-bound $\mathrm{G} \alpha_{\mathrm{t}}$ has been shown to possess some ability to activate cGMP phosphodiesterase in vitro (Kutuzov and Pfister, 1994). This raises the possibility that the reduced flash sensitivity in $G \gamma_{1}$ knock-out rods arose in part from the desensitizing effect of spontaneous cascade activity driven by free $\mathrm{G} \alpha$. To test this possibility, we measured the cellular noise by analyzing the outer segment current recorded in darkness and in the presence of saturating steady light, which closes all of the cGMP-sensitive channels and silences all but instrumental noise (Fig. 9A). Assuming that these sources of noise were independent and additive, the difference of these two power spectra (dark - light) yielded the difference spectrum (Fig. 9B) with characteristic cascade noise variance at low frequencies (Rieke and Baylor, 1998; Burns et al., 2002). All G $\gamma_{1}$ knock-out rods showed much lower cellular dark noise variance between 0.1 and $20 \mathrm{~Hz}$ (Table 4). Thus, the reduced flash sensitivity does not arise from the desensitizing effect of spontaneously active free $\mathrm{G} \alpha_{\mathrm{t}}{ }^{-}$ PDE complex but rather likely results from reduced amplification as a result of the gross reduction in $\mathrm{G} \alpha_{\mathrm{t}}$ expression and/or activity.

To measure amplification directly, we fit the Lamb and Pugh activation model (Pugh and Lamb, 1993) to the rising phases of families of flash responses from wild-type and $\mathrm{G} \gamma_{1}$ knock-out rods. This analysis requires precisely knowing the number of photoexcited rhodopsin molecules produced by each flash, which normally can be empirically determined by variance-to-mean analysis (Krispel et al., 2006). However, quantal fluctuations were too small to be resolved in the insensitive $\mathrm{G} \gamma_{1}$ knock-out rods, and so the number of photoexcited rhodopsin molecules was estimated by the cellular dimensions. Consistent with previous studies, wild-type mouse rods showed amplification constants of near $10 \mathrm{~s}^{-2}$ (see Table 4). In contrast, $\mathrm{G} \gamma_{1}$ knock-out rods had amplification constants 24-fold smaller. However, because $\mathrm{G} \gamma_{1}$ knock-out rods were approximately two-thirds of normal length, and the amplification constant is inversely proportional to the cytoplasmic volume (Lamb and Pugh, 1992), this change in amplification constant corresponds to an approximately 40 -fold change in the rate of transducin activation. Thus, the $\sim 50$-fold change in the expression level of $\mathrm{G} \alpha_{\mathrm{t}}$ expression
WT

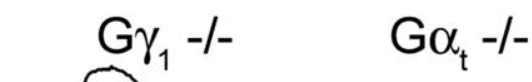

l $\log 1$ 2.5 1.3 0.1 $-1.1$ $-2.3$

Figure 7. ERG analysis of light responses in $G \gamma_{1}$ knock-out mice. $\boldsymbol{A}$, Representative ERG recordings from 31- to 33-d-old wild-type, intensity measured in $\mathrm{cd} \cdot \mathrm{s} / \mathrm{m}^{2}$. B , The dependencies of a- and b-wave amplitudes in each animal type on the flash intensity. The curve

$$
A=A_{\max , 1} \frac{I^{n_{1}}}{I^{n_{1}}+I_{\mathrm{h}, 1}^{n_{1}}}+A_{\max , 2} \frac{I^{n_{2}}}{I^{n_{2}}+I_{\mathrm{h}, 2}^{n_{2}}}
$$

\section{b-wave}

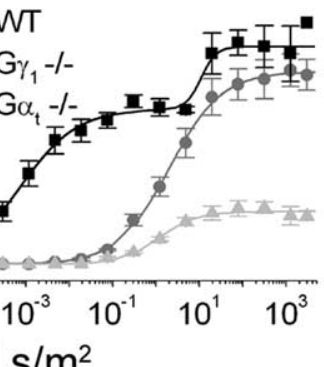

flash intensity, $\mathrm{Cd} \mathrm{s} / \mathrm{m}^{2}$

where $A_{\max }$ is the maximal amplitude, / is the flash intensity, $n$ is the Hill coefficient, and $I_{\mathrm{h}}$ is the half-saturating light intensity. In wild-type mice, the first term represents the contribution from rods, and the second represents the contribution from cones (observed in bright light). The parameters of the fits are summarized in Table 3.

is similar to both the $\sim 40$-fold change in transducin activation rate and the $\sim 70$-fold decrease change in sensitivity $\left(I_{\mathrm{o}}\right)$, with the latter also being affected by deactivation and perhaps calcium feedback mechanisms, which may have been a bit different in the degenerating $\mathrm{G} \gamma_{1}$ knock-out rods.

\section{Discussion}

The cellular content of the transducin heterotrimer is set by the expression of $\mathrm{G} \boldsymbol{\beta}_{1} \gamma_{1}$

The first major result of our study is that the amounts of both $\mathrm{G} \alpha_{\mathrm{t}}$ and $\mathrm{G} \beta_{1}$ in rods are dependent on the expression of $\mathrm{G} \gamma_{1}$. Although the $G \beta_{1}$ reduction is rather intuitive because the G-protein $\beta \gamma$-subunit complexes always exist as single functional units, the downregulation of $\mathrm{G} \alpha_{\mathrm{t}}$ is not and contrasts with the observation that the expression of $\mathrm{G} \beta_{1} \gamma_{1}$ is not affected by the lack of $\mathrm{G} \alpha_{\mathrm{t}}$ (Calvert et al., 2000). Therefore, the cellular content of the entire heterotrimer in rods is set by the level of G $\beta_{1} \gamma_{1}$. Because $\mathrm{G} \alpha_{\mathrm{t}}$ transcript remains unchanged in both $\mathrm{G} \gamma_{1}$ knock-out and heterozygous mice, the most straightforward explanation of the $\mathrm{G} \alpha_{\mathrm{t}}$ reduction is that its expression level is adjusted posttranslationally, through the proteolysis of $\mathrm{G} \alpha_{\mathrm{t}}$ molecules not associated with $G \beta_{1} \gamma_{1}$. G $\beta_{1} \gamma_{1}$ could protect $G \alpha_{t}$ either directly, by masking $\mathrm{G} \alpha_{\mathrm{t}}$ sites susceptible to ubiquitination and/or proteolysis, or indirectly, by trafficking the entire transducin to the rod outer segment, which does not contain proteasomes (Obin et al., 2002). The lack of $G \gamma_{1}$ could also affect $G \alpha_{t}$ folding, although indirectly (see below). 
Table 3. The fitting parameters of the amplitude-intensity plots in Figure $7 B$

\begin{tabular}{|c|c|c|c|c|c|c|}
\hline & $I_{\mathrm{h}, 1}\left(\mathrm{~cd} \cdot \mathrm{s} / \mathrm{m}^{2}\right)$ & $n_{1}$ & $A_{\max , 1}(\mu \mathrm{V})$ & $I_{\mathrm{h}, 2}\left(\mathrm{~cd} \cdot \mathrm{s} / \mathrm{m}^{2}\right)$ & $n_{2}$ & $A_{\max , 2}(\mu \mathrm{V})$ \\
\hline \multicolumn{7}{|l|}{ a-wave } \\
\hline WT & $0.48 \pm 0.07$ & $0.60 \pm 0.04$ & $315 \pm 8$ & $335 \pm 102$ & $1.71 \pm 0.75$ & $82 \pm 14$ \\
\hline $\mathrm{G} \gamma_{1}-/-$ & $17.7 \pm 2.8$ & $0.62 \pm 0.05$ & $118 \pm 3$ & & & \\
\hline $\begin{array}{l}\mathrm{G} \alpha_{\mathrm{t}}-/- \\
\text { b-wave }\end{array}$ & & & & $4.7 \pm 0.8$ & $1.5 \pm 0.5$ & $23 \pm 1$ \\
\hline WT & $0.0008 \pm 0.0001$ & $0.67 \pm 0.08$ & $475 \pm 11$ & $11 \pm 2$ & $2.5 \pm 0.68$ & $191 \pm 13$ \\
\hline $\mathrm{G} \gamma_{1}-/-$ & $2.05 \pm 0.09$ & $0.73 \pm 0.02$ & $589 \pm 4$ & & & \\
\hline $\mathrm{G} \alpha_{\mathrm{t}}-1-$ & & & & $1.18 \pm 0.12$ & $0.98 \pm 0.09$ & $161 \pm 3$ \\
\hline
\end{tabular}

The data are taken from at least four animals of each type and shown as mean \pm SEM.

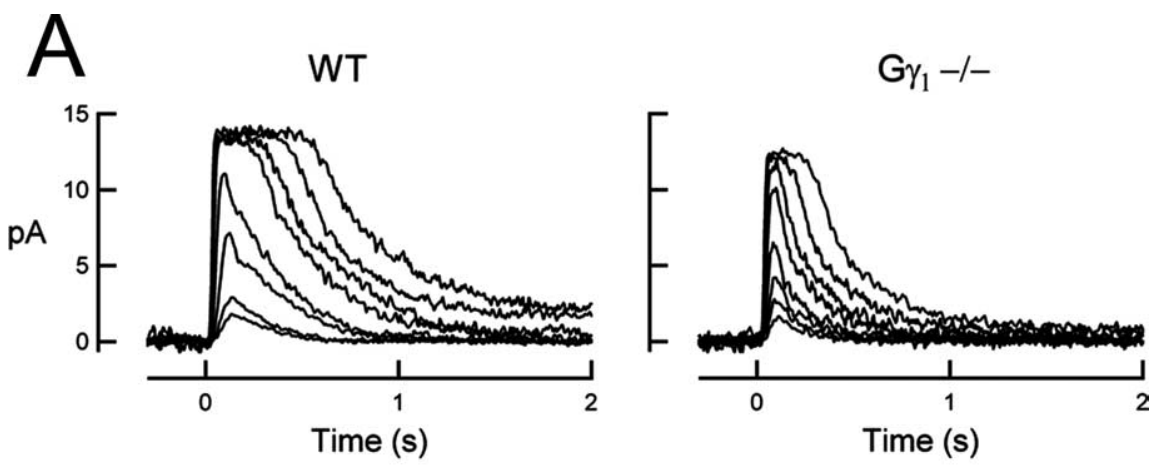

B

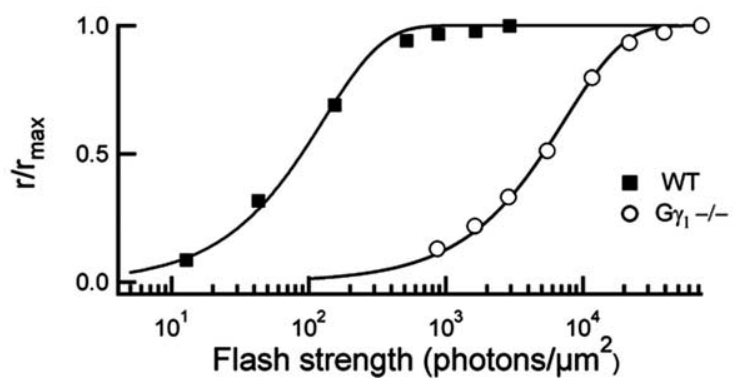

Figure 8. Light responses of individual wild-type and $G \gamma_{1}$ knock-out rods. $\boldsymbol{A}$, Families of flash responses from representative wild-type and $G \gamma_{1}$ knock-out rods. Flash strengths ranged from 6.82 to 2937 photons/ $\mu \mathrm{m}^{2}$ for WT and from 872 to 73698 photons $/ \mu \mathrm{m}^{2}$ for $\mathrm{G} \gamma_{1}$ knock-outs. $\boldsymbol{B}$, Normalized response amplitudes as a function of flash strength for the $\mathrm{G} \gamma_{1}$ knock-out rod shown in $\boldsymbol{A}$ (open circles) and a rod from (57BL/6 wild-type mouse (filled squares). Points were fitted by saturating exponential functions. Dark currents were $16.5 \mathrm{pA}$ (wild type) and $12.3 \mathrm{pA}$ (G $\gamma_{1}$ knock-out).

The expression level of $\mathrm{G} \beta_{1} \gamma_{1}$ itself may be tuned by posttranslational mechanisms also. $\mathrm{G} \gamma_{1}$ contains specific ubiquitination sites tagging $G \beta_{1} \gamma_{1}$ for proteolysis by the $26 \mathrm{~S}$ proteasome (Obin et al., 2002). This ubiquitination has been shown to be regulated by phosducin in vitro (Obin et al., 2002), and phosducin knock-out results in $\sim 36 \%$ loss of G $\beta_{1} \gamma_{1}$ in rods (Sokolov et al., 2004; Krispel et al., 2007).

The $\mathrm{G} \gamma_{1}$ knock-out phenotype reveals a striking in vivo example of the dependency of $\mathrm{G} \alpha$ protein levels on the presence of functional $G \beta \gamma$, which likely reflects a general principle for regulation of $\mathrm{G}$-protein expression. Other similar findings include a modest $\mathrm{G} \alpha_{\mathrm{i} 3}$ decrease in the brain of $\mathrm{G} \gamma_{3}$ knockout mice (Schwindinger et al., 2004) and a major reduction of $\mathrm{G} \alpha_{\text {olf }}$ in the striatum of $\mathrm{G} \gamma_{7}$ knock-outs (Schwindinger et al., 2003). The same concept that the expression level of a multisubunit protein complex may be set by the tightly regulated expression of a single subunit extends far beyond G-proteins. For example, the cellular content of the multi-subunit GTPase-activating complex (RGS9·G $\beta 5 \cdot \mathrm{R} 9 \mathrm{AP}$ ) responsible for timely inactivation of transducin during the recovery from a photoresponse is set by the expression of R9AP. The levels of other two components, RGS9 and G $\beta 5$, closely match R9AP: R9AP knock-out eliminates nearly all RGS9 and G $\beta 5$ from the rods (Keresztes et al., 2004), whereas R9AP overexpression leads to their overexpression (Krispel et al., 2006).

\section{Rod outer segment localization of transducin requires heterotrimer formation}

Our second major finding is that $\mathrm{G} \gamma_{1}$ knockout causes constitutive mislocalization of $\mathrm{G} \alpha_{\mathrm{t}}$ from rod outer segments, which resembles $\mathrm{G} \beta_{1} \gamma_{1}$ mislocalization in $\mathrm{G} \alpha_{\mathrm{t}}$ knock-out mice. This supports the hypothesis that transducin heterotrimer is retained on the photoreceptor disc membranes in outer segments through the combined action of two lipid modifications, $\mathrm{G} \gamma_{1}$ isoprenylation and $\mathrm{G} \alpha_{\mathrm{t}}$ acylation [for review, see Calvert et al. (2006); for the most recent updates, see Kerov et al. (2007) and Rosenzweig et al. (2007)]. Interestingly, the distribution of $\mathrm{G} \alpha_{\mathrm{t}}$ in $\mathrm{G} \gamma_{1}$ knock-out rods and $\mathrm{G} \beta_{1} \gamma_{1}$ in $\mathrm{G} \alpha_{\mathrm{t}}$ knock-out rods is somewhere in between the dark- and light-adapted distributions in wild-type rods, with more transducin present in the outer segment than in lightadapted wild-type mice. According to current consensus (Calvert et al., 2006), transducin translocation arises from the diffusion of individual $\mathrm{G} \alpha_{\mathrm{t}}$ and $\mathrm{G} \beta_{1} \gamma_{1}$ subunits, separated from one another by photoexcited rhodopsin. Therefore, in the absence of heterotrimer formation, the subcellular distribution of $\mathrm{G} \alpha_{\mathrm{t}}$ or $\mathrm{G} \beta_{1} \gamma_{1}$ is predicted to be set by their membrane/cytosol distribution coefficients and by relative membrane densities of various subcellular compartments. Because outer segments are rich in membranes, fair fractions of individual subunits would be expected to localize there, just as we observe in both $\mathrm{G} \alpha_{\mathrm{t}}$ and $\mathrm{G} \gamma_{1}$ knock-out rods. However, in wild-type rods, transducin subunits translocating from the outer segment re-form the heterotrimer in the inner segment, which is likely to be trapped by the membranes of the inner segment. This will cause a larger overall degree of translocation than could be achieved by individual subunits alone. Our results support an emerging concept in G-protein cell biology, based primarily on cell culture studies, in which the localization of G-proteins to sites of their function (usually plasma membrane) requires the assembly of a completely lipidated heterotrimer (for review, see Marrari et al., 2007).

\section{How does light activate $\mathrm{G} \alpha_{\mathrm{t}}$ in $\mathrm{G} \gamma_{1}$ knock-out rods?}

Our next important finding is that rods of $\mathrm{G} \gamma_{1}$ knock-out mice are able to produce photoresponses. In contrast, $\mathrm{G} \alpha_{\mathrm{t}}$ knockout rods expressing normal levels of $\mathrm{G} \beta_{1} \gamma_{1}$ are completely insensitive to light. This indicates that the small amount ( $\sim 2 \%$ normal) of the $\mathrm{G} \alpha_{\mathrm{t}}$ located in outer segments of $\mathrm{G} \gamma_{1}$ knock-out rods is completely functional. But how could it be activated without $\mathrm{G} \beta_{1} \gamma_{1}$ ? One possibility is that rhodopsin can activate monomeric $\mathrm{G} \alpha_{\mathrm{t}}$, although studies obtained with re- 
Table 4. Characteristics of single cell responses from dark-adapted rods with and without $\mathrm{G} \gamma_{1}$

\begin{tabular}{|c|c|c|c|c|c|c|c|}
\hline & Dark current $(\mathrm{pA})$ & $\begin{array}{l}\text { Dim flash time to } \\
\text { peak (ms) }\end{array}$ & $\tau_{\text {rec }}(\mathrm{ms})^{a}$ & $\begin{array}{l}\text { Integration time } \\
\text { (ms) }\end{array}$ & $I_{0}\left(\text { photons } \cdot \mu \mathrm{m}^{-2}\right)^{b}$ & Cellular noise $\sigma^{2}\left(\mathrm{pA}^{2}\right)^{c}$ & $\begin{array}{l}\text { Amplification constant } \\
\left(s^{-2}\right)\end{array}$ \\
\hline $\mathrm{G} \gamma_{1}-1-$ & $9.9 \pm 0.9(n=12)$ & $102 \pm 15(n=12)$ & $142 \pm 15(n=12)$ & $193 \pm 24(n=12)$ & $3991 \pm 471(n=12)$ & $0.00927 \pm 0.00336(n=9)$ & $0.367 \pm 0.043(n=12)$ \\
\hline WT & $13.6 \pm 0.7(n=29)$ & $114 \pm 6(n=19)$ & $174 \pm 11(n=19)$ & $254 \pm 19(n=19)$ & $59.4 \pm 3.0(n=19)$ & $0.0575 \pm 0.0199(n=8)$ & $8.87 \pm 0.55(n=17)$ \\
\hline
\end{tabular}

${ }^{a \tau}$ rec was determined by fitting a single-exponential function to the final falling phase of the dim flash response.

${ }^{b}$ Flash strength $(500 \mathrm{~nm})$ that elicited a half-maximal response.

`Noise variance for individual cells was calculated by integrating difference (dark - light) power spectra over a bandwidth of $0.1-20 \mathrm{~Hz}$. All other parameters were determined as by Krispel et al. (2003).

constituted purified proteins (Fung, 1983; Herrmann et al., 2006) indicate this would be with significantly lower efficiency. Alternatively, $\mathrm{G} \alpha_{\mathrm{t}}$ activation may be driven by heterotrimer formed between $\mathrm{G} \alpha_{\mathrm{t}}$ and the small fraction of remaining $\mathrm{G} \beta_{1}$ associated with another $\mathrm{G} \gamma$ subunit and/or another $\mathrm{G} \beta \gamma$ complex present in the rod. This is consistent with observations that $\mathrm{G} \beta \gamma$ subunits are fairly promiscuous in regards to their $\mathrm{G} \alpha$ interactions (Clapham and Neer, 1997) and that the activation of $\mathrm{G} \alpha_{\mathrm{t}}$ by rhodopsin could be supported by substoichiometric amounts of G $\beta \gamma$ (Fung, 1983). Despite our inability to identify alternative $G \gamma$ partners for $G \beta_{1}$ in $G \gamma_{1}$ knockout rods, we strongly favor the latter explanation because the reduction in the $\mathrm{G} \alpha_{\mathrm{t}}$ correlated with the reduction in amplification constant, indicating that the remaining $\mathrm{G} \alpha_{\mathrm{t}}$ was activated at its physiological rate. In addition, $\mathrm{G} \gamma_{1}$ knockout rods showed reduced cellular dark noise, consistent with the reduction in heterotrimer expression and the corresponding lower rate of its spontaneous activation.

\section{Why does the absence of $\mathrm{G} \gamma_{1}$ lead to photoreceptor degeneration?}

Our fourth major observation is that $\mathrm{G} \gamma_{1}$ knock-out rods undergo a fairly rapid degeneration. It is commonly accepted that in all forms of retinal degeneration, photoreceptors eventually die via apoptosis, but the molecular events triggering cell death are specific to each degeneration type and range from abnormal light signaling to protein mislocalization and misfolding [for review, see Rattner et al. (1999) and Hartong et al. (2006)]. Because photoreceptor degeneration in $\mathrm{G} \gamma_{1}$ knock-out mice was not rescued by the knock-out of $\mathrm{G} \alpha_{\mathrm{t}}$, which completely abolishes rod light responses, it is not likely that $\mathrm{G} \gamma_{1}$ knock-out rods die as a result of abnormal $\mathrm{G} \alpha_{\mathrm{t}}$ signaling without $\mathrm{G} \beta_{1} \gamma_{1}$. Therefore, it is more likely that $\mathrm{G} \gamma_{1}$ knock-out rods degenerate because of the stress imposed by massive production of $\mathrm{G} \beta_{1}$ unable to form a functional dimer without $\mathrm{G} \gamma_{1}$. A more detailed hypothesis could be considered based on the mechanism of the G $\beta \gamma$ assembly recently proposed by Kubota et al. (2006), Lukov et al. (2006), and Wells et al. (2006) and reviewed by Marrari et al. (2007) and Willardson and Howlett (2007). In this model, the newly synthesized G $\beta$ binds to the chaperone CCT, which assists folding of a number of major proteins. This is followed by the binding of phosducin-like protein, PhLP, forming a ternary complex with $\mathrm{G} \beta$ and CCT, PhLP phosphorylation, and release of the PhLP-G $\beta$ complex from the chaperone. PhLP-G $\beta$ then binds $G \gamma$, forming the mature $G \beta \gamma$, and PhLP is released to catalyze another round of $\mathrm{G} \beta \gamma$ formation. Therefore, the lack of $\mathrm{G} \gamma_{1}$ may prevent normal PhLP recycling, causing a major G $\beta_{1}$ “jam” at the CCT chaperone, impairing its ability to process $\mathrm{G} \beta_{1}$ and other cellular proteins, and eventually triggering cell death. Elucidating whether this type of cell death is caused by the added load on the proteasomes or is triggered by an unknown pathway downstream of jammed CCTs remains a subject of future studies. Interestingly, the folding of $\mathrm{G} \alpha_{\mathrm{t}}$ was also demonstrated to be assisted by CCT in vitro, and the $\mathrm{G} \alpha_{\mathrm{t}}$-CCT complex was precipitated from isolated rat retinas (Farr et al., 1997). Therefore, the $\mathrm{G} \alpha_{\mathrm{t}}$ reduction in the $\mathrm{G} \gamma_{1}$ knock-out rods may be explained by any combination of its protection by $\mathrm{G} \beta_{1} \gamma_{1}$ (see above) and its impaired folding because of jammed chaperones.

Finally, we should mention another mouse mutation, the large chromosome inversion encompassing nearly the entire chromosome 4 called $R d 4$ (Roderick et al., 1997). Homozygous inheritance of the $R d 4$ chromosome is lethal, whereas the $R d 4+$ / - phenotype is characterized by photoreceptor degeneration significantly more rapid and severe than in $\mathrm{G} \gamma_{1}$ knock-out mice. Kitamura et al. (2006) demonstrated that the distal breakpoint of this inversion lies in the second intron of the $G \beta_{1}$ gene, found that the retinal level of the $G \beta_{1}$ in young mice is reduced approximately twofold, and suggested that this reduction serves as the primary cause of degeneration. Our data do not support this hypothesis, because $\sim 40 \% \mathrm{G} \beta_{1}$ reduction in $\mathrm{G} \gamma_{1}+/-$ animals causes no degeneration even in old animals, and even more importantly, $\sim 98 \% \mathrm{G} \beta_{1}$ reduction in $\mathrm{G} \gamma_{1}$ knock-out causes degeneration less severe than in $R d 4+/-$ mice. Therefore, the ret- 
inal degeneration in $R d 4$ mice is likely to involve mechanisms additional to the disruption of the $\mathrm{G} \beta_{1}$ gene.

\section{References}

Arshavsky VY, Lamb TD, Pugh Jr EN (2002) G proteins and phototransduction. Annu Rev Physiol 64:153-187.

Burns ME, Baylor DA (2001) Activation, deactivation, and adaptation in vertebrate photoreceptor cells. Annu Rev Neurosci 24:779-805.

Burns ME, Mendez A, Chen J, Baylor DA (2002) Dynamics of cyclic GMP synthesis in retinal rods. Neuron 36:81-91.

Calvert PD, Krasnoperova NV, Lyubarsky AL, Isayama T, Nicolo M, Kosaras B, Wong G, Gannon KS, Margolskee RF, Sidman RL, Pugh Jr EN, Makino CL, Lem J (2000) Phototransduction in transgenic mice after targeted deletion of the rod transducin alpha-subunit. Proc Natl Acad Sci USA 97:13913-13918.

Calvert PD, Strissel KJ, Schiesser WE, Pugh Jr EN, Arshavsky VY (2006) Light-driven translocation of signaling proteins in vertebrate photoreceptors. Trends Cell Biol 16:560-568.

Clapham DE, Neer EJ (1997) G protein beta gamma subunits. Annu Rev Pharmacol Toxicol 37:167-203.

Fain GL, Matthews HR, Cornwall MC, Koutalos Y (2001) Adaptation in vertebrate photoreceptors. Physiol Rev 81:117-151.

Farr GW, Scharl EC, Schumacher RJ, Sondek S, Horwich AL (1997) Chaperonin-mediated folding in the eukaryotic cytosol proceeds through rounds of release of native and nonnative forms. Cell 89:927-937.

Fulton AB, Rushton WA (1978) The human rod ERG: correlation with psychophysical responses in light and dark adaptation. Vision Res 18:793-800.

Fung BK (1983) Characterization of transducin from bovine retinal rod outer segments. I. Separation and reconstitution of the subunits. J Biol Chem 258:10495-10502.

Hartong DT, Berson EL, Dryja TP (2006) Retinitis pigmentosa. Lancet 368:1795-1809.

Heck M, Hofmann KP (2001) Maximal rate and nucleotide dependence of rhodopsin-catalyzed transducin activation: initial rate analysis based on a double displacement mechanism. J Biol Chem 276:10000-10009.

Herrmann R, Heck M, Henklein P, Hofmann KP, Ernst OP (2006) Signal transfer from GPCRs to $\mathrm{G}$ proteins: role of the $\mathrm{G}$ alpha $\mathrm{N}$-terminal region in rhodopsin-transducin coupling. J Biol Chem 281:30234-30241.

Keresztes G, Martemyanov KA, Krispel CM, Mutai H, Yoo PJ, Maison SF, Burns ME, Arshavsky VY, Heller S (2004) Absence of the RGS9.G $\beta 5$ GTPase-activating complex in photoreceptors of the R9AP knockout mouse. J Biol Chem 279:1581-1584.

Kerov V, Rubin WW, Natochin M, Melling NA, Burns ME, Artemyev NO (2007) N-terminal fatty acylation of transducin profoundly influences its localization and the kinetics of photoresponse in rods. J Neurosci 27:10270-10277.

Kitamura E, Danciger M, Yamashita C, Rao NP, Nusinowitz S, Chang B, Farber DB (2006) Disruption of the gene encoding the betal-subunit of transducin in the Rd4/+ mouse. Invest Ophthalmol Vis Sci 47:1293-1301.

Krispel CM, Chen CK, Simon MI, Burns ME (2003) Prolonged photoresponses and defective adaptation in rods of $\mathrm{G} \beta 5-/-$ mice. J Neurosci 23:6965-6971.

Krispel CM, Chen D, Melling N, Chen YJ, Martemyanov KA, Quillinan N, Arshavsky VY, Wensel TG, Chen CK, Burns ME (2006) RGS expression rate-limits recovery of rod photoresponses. Neuron 51:409-416.

Krispel CM, Sokolov M, Chen YM, Song H, Herrmann R, Arshavsky VY, Burns ME (2007) Phosducin regulates the expression of transducin $\beta \gamma$ subunits in rod photoreceptors and does not contribute to phototransduction adaptation. J Gen Physiol 130:303-312.

Kubota S, Kubota H, Nagata K (2006) Cytosolic chaperonin protects folding intermediates of $\mathrm{G} \beta$ from aggregation by recognizing hydrophobic beta-strands. Proc Natl Acad Sci USA 103:8360-8365.

Kutuzov M, Pfister C (1994) Activation of the retinal cGMP-specific phosphodiesterase by the GDP-loaded $\alpha$-subunit of transducin. Eur J Biochem 220:963-971.

Lamb TD, Pugh Jr EN (1992) A quantitative account of the activation steps involved in phototransduction in amphibian photoreceptors. J Physiol 449:719-758.

Livak KJ, Schmittgen TD (2001) Analysis of relative gene expression data using real-time quantitative PCR and the $2(\Delta \Delta \mathrm{C}(\mathrm{T}))$ method. Methods 25:402-408.
Lobanova ES, Finkelstein S, Song H, Tsang SH, Chen C-K, Sokolov M, Skiba NP, Arshavsky VY (2007) Transducin translocation in rods is triggered by saturation of the GTPase-activating complex. J Neurosci 27:1151-1160.

Loew A, Ho YK, Blundell T, Bax B (1998) Phosducin induces a structural change in transducin $\beta \gamma$. Structure 6:1007-1019.

Lukov GL, Myung CS, McIntire WE, Shao J, Zimmerman SS, Garrison JC, Willardson BM (2004) Role of the isoprenyl pocket of the G protein $\beta \gamma$ subunit complex in the binding of phosducin and phosducin-like protein. Biochemistry 43:5651-5660.

Lukov GL, Baker CM, Ludtke PJ, Hu T, Carter MD, Hackett RA, Thulin CD, Willardson BM (2006) Mechanism of assembly of G protein $\beta \gamma$ subunits by protein kinase CK2-phosphorylated phosducin-like protein and the cytosolic chaperonin complex. J Biol Chem 281:22261-22274.

Makino ER, Handy JW, Li T, Arshavsky VY (1999) The GTPase activating factor for transducin in rod photoreceptors is the complex between RGS9 and type 5 G protein beta subunit. Proc Natl Acad Sci USA 96:1947-1952.

Marrari Y, Crouthamel M, Irannejad R, Wedegaertner PB (2007) Assembly and trafficking of heterotrimeric $\mathrm{G}$ proteins. Biochemistry 46:7665-7677.

Obin M, Lee BY, Meinke G, Bohm A, Lee RH, Gaudet R, Hopp JA, Arshavsky VY, Willardson BM, Taylor A (2002) Ubiquitylation of the transducin $\beta \gamma$ subunit complex. Regulation by phosducin. J Biol Chem 277:44566-44575

Peng Y, Robishaw JD, Levine MA, Yau K (1992) Retinal rods and cones have distinct $G$ protein $\beta$ and $\gamma$ subunits. Proc Natl Acad Sci USA 89:10882-10886.

Peng YW, Senda T, Hao Y, Matsuno K, Wong F (2003) Ectopic synaptogenesis during retinal degeneration in the royal college of surgeons rat. Neuroscience 119:813-820.

Petters RM, Alexander CA, Wells KD, Collins EB, Sommer JR, Blanton MR, Rojas G, Hao Y, Flowers WL, Banin E, Cideciyan AV, Jacobson SG, Wong F (1997) Genetically engineered large animal model for studying cone photoreceptor survival and degeneration in retinitis pigmentosa. Nat Biotechnol 15:965-970.

Pfaffl MW (2001) A new mathematical model for relative quantification in real-time RT-PCR. Nucl Acids Res 29:e45.

Pugh Jr EN, Lamb TD (1993) Amplification and kinetics of the activation steps in phototransduction. Biochim Biophys Acta 1141:111-149.

Pugh Jr EN, Falsini B, Lyubarsky AL (1998) The origin of the major rod- and cone-driven components of the rodent electroretinogram and the effect of age and light-rearing history on the magnitude of these components. In: Photostasis and related phenomena (Thistle W, ed), pp 93-128. New York: Plenum.

Pugh Jr EN, Nikonov S, Lamb TD (1999) Molecular mechanisms of vertebrate photoreceptor light adaptation. Curr Opin Neurobiol 9:410-418.

Rattner A, Sun H, Nathans J (1999) Molecular genetics of human retinal disease. Annu Rev Genet 33:89-131.

Rieke F, Baylor DA (1998) Origin of reproducibility in the responses of retinal rods to single photons. Biophys J 75:1836-1857.

Roderick TH, Chang B, Hawes NL, Heckenlively JR (1997) A new dominant retinal degeneration ( $\mathrm{Rd} 4)$ associated with a chromosomal inversion in the mouse. Genomics 42:393-396.

Rosenzweig DH, Nair KS, Wei J, Wang Q, Garwin G, Saari JC, Chen CK, Smrcka AV, Swaroop A, Lem J, Hurley JB, Slepak VZ (2007) Subunit dissociation and diffusion determine the subcellular localization of rod and cone transducins. J Neurosci 27:5484-5494.

Saszik SM, Robson JG, Frishman LJ (2002) The scotopic threshold response of the dark-adapted electroretinogram of the mouse. J Physiol (Lond) 543:899-916.

Schwindinger WF, Betz KS, Giger KE, Sabol A, Bronson SK, Robishaw JD (2003) Loss of G protein $\gamma 7$ alters behavior and reduces striatal $\alpha_{\text {olf }}$ level and cAMP production. J Biol Chem 278:6575-6579.

Schwindinger WF, Giger KE, Betz KS, Stauffer AM, Sunderlin EM, Sim-Selley LJ, Selley DE, Bronson SK, Robishaw JD (2004) Mice with deficiency of $\mathrm{G}$ protein $\gamma 3$ are lean and have seizures. Mol Cell Biol 24:7758-7768.

Sokolov M, Lyubarsky AL, Strissel KJ, Savchenko AB, Govardovskii VI, Pugh Jr EN, Arshavsky VY (2002) Massive light-driven translocation of transducin between the two major compartments of rod cells: a novel mechanism of light adaptation. Neuron 34:95-106.

Sokolov M, Strissel KJ, Leskov IB, Michaud NA, Govardovskii VI, Arshavsky 
VY (2004) Phosducin facilitates light-driven transducin translocation in rod photoreceptors. Evidence from the phosducin knockout mouse. J Biol Chem 279:19149-19156.

Song JH, Song H, Wensel TG, Sokolov M, Martemyanov KA (2007) Localization and differential interaction of R7 RGS proteins with their membrane anchors R7BP and R9AP in neurons of vertebrate retina. Mol Cell Neurosci 35:311-319.

Strissel KJ, Sokolov M, Trieu LH, Arshavsky VY (2006) Arrestin translocation is induced at a critical threshold of visual signaling and is superstoichiometric to bleached rhodopsin. J Neurosci 26:1146-1153.

Ting TD, Goldin SB, Ho Y-K (1993) Purification and characterization of bovine transducin and its subunits. Methods Neurosci 15:180-195.
Wells CA, Dingus J, Hildebrandt JD (2006) Role of the chaperonin CCT/TRiC complex in G protein $\beta \gamma$-dimer assembly. J Biol Chem 281:20221-20232.

Willardson BM, Howlett AC (2007) Function of phosducin-like proteins in $\mathrm{G}$ protein signaling and chaperone-assisted protein folding. Cell Signal 19:2417-2427.

Zhang H, Huang W, Zhang H, Zhu X, Craft CM, Baehr W, Chen CK (2003) Light-dependent redistribution of visual arrestins and transducin subunits in mice with defective phototransduction. Mol Vis 9:231-237.

Zhang H, Hosier S, Terew JM, Zhang K, Cote RH, Baehr W (2005) Assay and functional properties of $\operatorname{PrBP}(\mathrm{PDEdelta})$, a prenyl-binding protein interacting with multiple partners. Methods Enzymol 403:42-56. 